\title{
Status Externalities and Low Birth Rates in Korea*
}

\author{
Seongeun Kim Michèle Tertilt Minchul Yum
}

February 2019

\section{PRELIMINARY AND INCOMPLETE - DO NOT CIRCULATE}

\begin{abstract}
South Korea has been experiencing a very low total fertility rate around 1.2 over the last two decades. A serious concern of the Korean government about low fertility is demonstrated by its billions-dollars worth spending in recent years. In this paper, we aim to understand why the birth rate is so low in Korea and to assess whether there is a reason for the government to be concerned. We ask what, if anything, could and should be done about the low fertility rate. To do so, we propose status externalities as a new reason for inefficiently low fertility. In our model with endogenous fertility, parents care about the education of their children relative to other parent's children. We find that the equilibrium is characterized by over-investment in education and under-investment in fertility, relative to the first best. We calibrate the model to Korean data to quantify the role of the status externality. We find that without it fertility would be $17 \%$ higher. We also find the externality plays a large role in explaining the fertility-income relationship, which is positive in Korea, in contrast to most other countries. We conduct several policy experiment and find that taxing education would not be desirable in welfare terms, even though it reduces the over-investment. Similarly, pronatal transfers do increase the fertility rate but are also not welfare improving. We conclude that more subtle policies are needed to rectify the friction introduced through status concerns.
\end{abstract}

Keywords: Fertility, Status, Externality, Education, Childlessness, Korea

\section{JEL codes: D13, E24, I2, J10, J13, D62, O40}

*Affiliations: Kim: Sejong University, Tertilt and Yum: University of Mannheim. We thank seminar participants at SUFE, Sogang, Korea Labor Institute, the University of Mannheim, AASLE in Seoul, Families and the Macroeconomy, EEA Cologne, ES Australasian Meeting in Auckland, AMES in Seoul for helpful comments. Financial support from the German Science Foundation through cluster CRC-TR-224 is gratefully acknowledged. 


\section{Introduction}

Forced to decide between giving her daughter siblings or an expensive education, Hong Sung-ok saw little choice. "I can't afford not to send my child to privation tuition, because everyone else does," says the 47-year-old insurance saleswoman. "I spend more than half my income on tutors and childcare expenses - it's really expensive... That's why I decided to have only one child." (Financial Times, Jan 2, 2013)

Since the early 2000s, South Korea has had an extremely low fertility rate. Currently it is at 1.2 children per woman - which is lower than in any other country, according to the World Bank database as of 2016. The Korean government has expressed concerns about the low birth rate, partly because it implies rapid population aging and a severe problem for the public pension system. Starting in 2006, the government thus launched a billion-dollar program to reverse the decline. For example in 2010, it spent 12.4 Billion USD on policies aimed to boost the birth rate.

In this paper we aim to understand why the birth rate is so low in Korea and to assess whether it justifies government intervention. The goal of the paper is twofold. First we aim to understand what drives the low fertility rate in Korea. In this context one also needs to understand the shape of the fertility-income relationship - which, in contrast to most other countries, is positive in Korea. Second, we want to understand what frictions may lead to inefficiencies in fertility decision-making. We then analyze policies that might potentially address the problem.

Even though it is conventionally believed that a low birth rate is undesirable, it is less clear why it should be a concern for the government. A reason frequently mentioned in the public media is the sustainability of the pay-as-you-go pension system in the long run. However, there has been little attention paid to the inefficiency of low fertility in the literature. ${ }^{1}$

We propose, and formally analyze, a new reason for why equilibrium fertility

\footnotetext{
${ }^{1}$ Two exceptions are Nishimura and Zhang (1992) and Schoonbroodt and Tertilt (2014). The former analyzes specificallly the role of a PAYGO pension system while the latter propose the lack of property rights from the perspective of parents as a source of inefficiency of low fertility.
} 
rates may be too low: status externalities. ${ }^{2}$ The idea we analyze in this paper is as follows. Assume parents care about the education of their children relative to other parent's children. Parents choosing private education spending (such as private cram schools) will then tend to over-invest into their children. This drives up education costs per child and hence makes children very costly. In such a world parents have few children and invest too much in each. We argue that this mechanism is particularly relevant in Korea where spending on private after-school programs reaches astronomical heights. Overall 1.63\% of GDP is spent on after-school education - with an average monthly spending per child of 250 USD.

To explore this idea we build a quantitative model with endogenous fertility and concerns for relative education. The model is an over-lapping generations model with heterogeneous agents. Parents choose the number of children and how much to invest into their schooling. The model incorporates a quantity-quality trade-off in that parents care about the number of children but also the human capital of their children. Human capital is produced through parental education spending, parental own human capital, and luck - that is, some kids are born smarter than others, independent of parental inputs. The model features heterogeneity as follows. Agents differ by human capital (which results from parental choices and a random component) and in how much they care about their own consumption vs. having children. This latter preference difference is also randomly chosen. In contrast to standard quantity-quality tradeoff models, we add status concerns to the quality dimension. Parents derive utility from the human capital of their children relative to other offsprings's human capital. This leads to an externality where aggregate education spending will be inefficiently high.

We solve the model numerically and calibrate it to data from Korea. We then use the calibrated model to understand fertility choices in Korea and to conduct policy experiments. The first finding is that the status externality plays an

\footnotetext{
${ }^{2}$ While there exists a sizeable literature on relative status concerns, they have not been explored in the context of fertility choice. The literature on general relative status concerns includes Abel (1990); Gali (1994); Ljungqvist and Uhlig. (2000); Genicot and Ray (2017) among others. The only exception perhaps are the verbal ideas of Easterlin (1966) who argues that aspirations formed during childhood affect fertility choices as adults.
} 
important role in the low birth rates in Korea. When shutting it down, fertility increases by $17 \%$ The reason is that the status externality drives up education investments, which makes children costly and parents to choose to have fewer children. This channel affects the poor the most. Therefore, when shutting down the externality, the relationship between fertility and income becomes a lot flatter. This is interesting because Korea displays a strong positive fertility-income relationship, which seems puzzling. In most other countries, fertility and income are negatively related. ${ }^{3}$ It appears then that the externality might be the reason behind the strong positive relationship. Once we shut it down, fertility is almost flat over income quintiles.

Given the inefficiency caused by the externality, we then explore various government policies. Because the equilibrium features overinvestment in private education, we introduce a tax on education spending. Interestingly, it does not work. Even though education spending goes down, fertility falls as well, since parents have to pay the tax, which is still a cost on having children. Moreover, in our quantitative model we assume upward status concerns, so that only the highest $10 \%$ education spenders cause the externality. So clearly a broad tax on everyone's educational spending makes a lot of people worse off without being directly targeted at those causing the externality. Secondly, we investigate pronatal transfers, i.e. government handouts per child similar to the German Kindergeld. ${ }^{4}$ We find that those do increase the fertility rate as intended. They also decrease educational spending somewhat. Yet they do not increase welfare either. We conclude that to increase the welfare of agents in our economy, we need more nuanced policies that are directly targeted at the source of the problem.

The next section describes the data and gives facts related to fertility and education spending in Korea. Section 3 sets up the model. The model is calibrated in Section 4. The importance of the status externality is discussed in Section 5 and policy experiments are conduced in Section 6. Section 7 concludes.

\footnotetext{
${ }^{3}$ Bar et al. (2018) argue that very recently even in the US we see an increase in fertility at the upper end of the income distribution. They relate it to the marketization of time.

${ }^{4}$ Guner, Kaygusuz, and Ventura (2019) analyze several types of child subsidies in a quantitative model calibrated to the U.S.
} 


\section{Fertility and Education in Korea}

We use the Korean Labor and Income Panel Study (KLIPS) data to document fertility and educational spending across households. The KLIPS is a longitudinal survey of representative samples of Korean households and individuals. The survey is conducted annually since 1998 on a sample of 5,000 households and members of the households. The data contains a rich variety of information including household demographics, education, labor market mobility, income, fertility, etc. We use the data from Wave 1 to Wave 18, the last of which was conducted in 2015.

As in Jones and Tertilt (2008), we use a cohort-based approach. Due to the length of the survey, we divide the whole samples into the two broad cohorts based on the women's birth year. Specifically, the earlier cohort includes all households with women born in between 1958 and 1966 (Cohort 1958-66) and the recent cohort includes those born in between 1967 and 1975 (Cohort 1967-75). The number of households is balanced between the two cohort groups: 1,175 for Cohort 1958-66 and 1,250 for Cohort 1967-75.

We define completed fertility as the number of children ever born to a woman. The completed fertility includes both intensive and extensive margins of fertility. The extensive margin of fertility is whether to have any child or not. The intensive margin is about the decision on the number of children when parents have decided to have at least one child. We look into the relationship between income and fertility along both intensive and extensive margins.

To measure permanent household income, we utilize the longitudinal feature of the data by taking long term averages (e.g., Chetty et al. 2014). Specifically, we use the average income of households in which the woman's age is between 38 to 42 and there are at least two observations within this age band. Our income measure is family income that combines labor income from both members of couples as well as capital income, but excludes income from social insurance and transfers. We adjust income for inflation using CPI. The unit of income is 10,000 Korean Won (KRW), which is similar to 10 US dollars. 
Figure 1: Fertility by income quintile

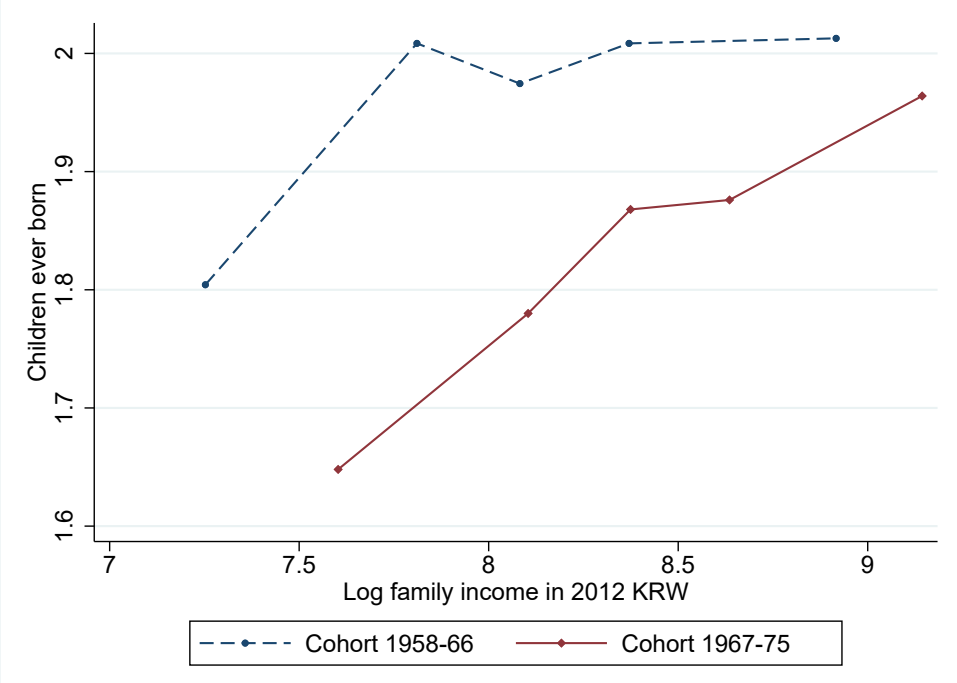

Notes: We group households into quintiles based on their long-term income and calculate the average completed fertility rate in each quintile for each cohort group, separately.

\subsection{Fertility by Income}

Figure 1 shows the cross-sectional relationship between the completed fertility and log income. We calculate the average number of children and average income in each income quintile. The dotted-line is for Cohort 1958-66 and the solid line is for Cohort 1967-75. First of all, completed fertility is lower for Cohort 1967-75. Second, The relationship is clearly positive. The positive relationship is stable across cohorts though it has become steeper for Cohort 1967-75. Table 1 shows that the number of children for Cohort 1958-66 increases from 1.80 for the lowest-income quintile to 2.01 for the highest-income quintile, while that for Cohort 1967-75 increases from 1.65 to 1.96. This implies that a higher family income is associated with a greater number of children and this relationship has become fairly stronger for the recent cohort.

To better quantify the relationship between fertility and income, we follow Jones and Tertilt (2008) and estimate the income elasticity of demand for children. The estimated elasticity for Cohort 1958-66 is 0.059 and that for Cohort 1967-75 is 0.112 . This finding may appear puzzling given the clearly negative elasticity 
Figure 2: Childlessness rate by income quintile

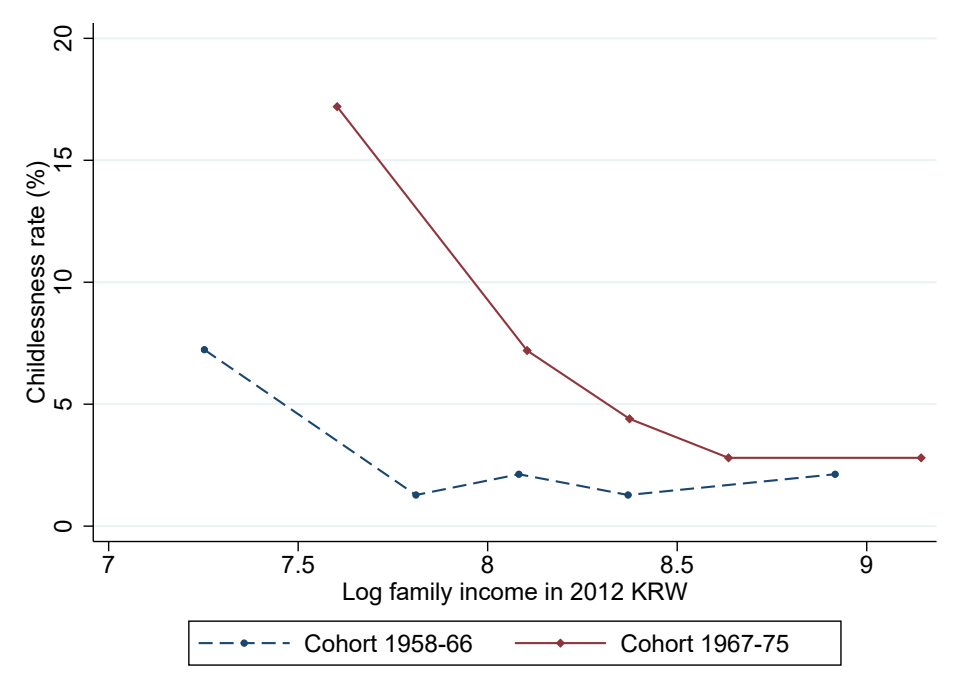

Notes: We group households into quintiles based on their long-term income and calculate the childlessness rate in each quintile for each cohort group, separately.

estimates reported in Jones and Tertilt (2008). For example, the elasticity estimate in their recent cohorts corresponding to our recent cohorts most closely, is around -0.2 .

A natural question one might have regarding the positive relationship between family income and fertility is to what extent this positive relationship is due to the intensive margin (number of children conditional on having any child) and due to the extensive margin (fraction of women without any child, or the childlessness rate). Figure 2 shows that the childlessness rate is higher for Cohort 1967-75 and has a negative relationship with income for both cohorts. Also, the relationship has become more negative for Cohort 1967-75. Table 1 shows that the childlessness rate for Cohort 1958-66 decreases from $7.2 \%$ for the lowest-income quintile to $2.1 \%$ for the highest-income quintile, while that for Cohort $1967-75$ decreases from $17.2 \%$ to $2.8 \%$. This clearly shows that poor families are more likely to have no child especially in recent years. Also, this decomposition shows that the extensive margin is important to understand why the income elasticity of fertility has increased for the recent cohorts as shown in Figure 1. 
Table 1: Fertility and income

\begin{tabular}{ccccccc}
\hline Income & \multicolumn{2}{c}{ Number of children } & \multicolumn{2}{c}{ Childlessness rate (\%) } & \multicolumn{2}{c}{ Fraction of single (\%) } \\
quintile & $1958-66$ & $1967-75$ & $1958-66$ & $1967-75$ & $1958-66$ & $1967-75$ \\
\hline 1th & 1.80 & 1.65 & 7.23 & 17.20 & 20.85 & 25.60 \\
2nd & 2.00 & 1.78 & 1.28 & 7.20 & 2.13 & 6.00 \\
3rd & 1.97 & 1.87 & 2.13 & 4.40 & 2.13 & 1.20 \\
4th & 2.01 & 1.88 & 1.28 & 2.80 & 1.28 & 1.20 \\
5th & 2.01 & 1.96 & 2.13 & 2.80 & 2.13 & 0 \\
\hline
\end{tabular}

Notes: This table shows the average fertility rate, the childlessness rate, and the portion of single households in each income quintile for each cohort group, separately.

The decision on fertility is closely related to the marriage status of women. Single families tend to have lower income than couples and are more likely to have lower fertility. The number of single women is small in the data: 73 (6\% of total households) for Cohort 1958-66 and 96 (7\%) for the Cohort 1967-75. The last two columns of Table 1 shows the portion of single women for each income quintile. Single women include widowed, divorced, separated, and never married females. As expected, the fraction of single women is highest in the lowest-income quintile.

To check whether the previous results are driven by single women, we calculate the completed fertility and childlessness rate only with couples. Table A.1 shows that the positive relationship between the completed fertility and income and the negative relationship between the childlessness rate and income are still observed for both cohorts, although the slopes become flatter. ${ }^{5}$ The changes mostly come from the childlessness rate and from the lowest-income quintile as this group includes most of the single women.

\subsection{Private Expenditures in Education}

The KLIPS has two different types of questions regarding education spending. First, the survey asks about per-child spending on private education, such as

\footnotetext{
${ }^{5}$ See Figures B.1 and B.2 in the appendix.
} 
Figure 3: Expenditures on private education by income quintile
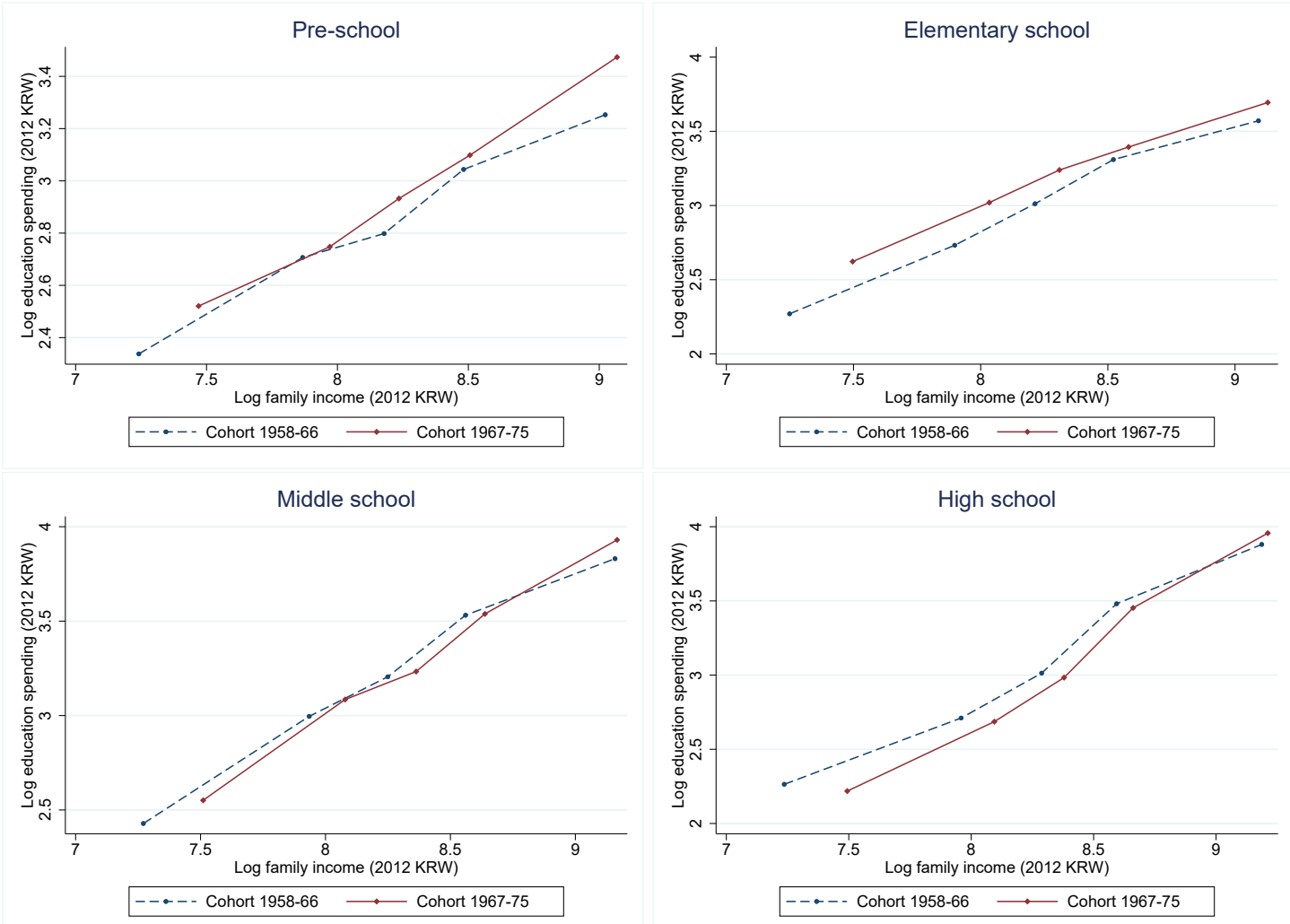

Notes: This figure shows the log expenditures on private education per child in each income quintile across the four stages of education for each cohort group, separately.

cram schools, for each child since Wave 3. Although this question excludes household expenditures on public education (e.g., tuitions), this is advantageous because we can observe the characteristics of the child to which the money is spent on. We use this survey question to investigate the cross-sectional relationship between expenditures on private education and income. Second, the survey also asks about total household-level expenditures on both private and public education since Wave 1 . This gives a very comprehensive measure of out-of-pocket educational spending. However, it is hard to control for each child's characteristics when there are multiple children in a household. Thus, we use this information to measure per-child spending on education relative to household income. 
Table 2: Income elasticity of demand for private education

\begin{tabular}{cccccccc}
\hline \multicolumn{2}{c}{ Pre-School } & \multicolumn{2}{c}{ Elementary } & \multicolumn{2}{c}{ Middle } & \multicolumn{2}{c}{ High } \\
$1967-75$ & $1958-66$ & $1967-75$ & $1958-66$ & $1967-75$ & $1958-66$ & $1967-75$ & $1958-66$ \\
\hline 0.52 & 0.60 & 0.73 & 0.66 & 0.76 & 0.83 & 0.86 & 1.00 \\
\hline
\end{tabular}

Notes: This table shows the income elasticity of demand for private education at each stage of education for each cohort group, separately. The elasticity corresponds to the slopes in Figure 3.

Figure 3 shows the relationship between the log of average education expenditures on private education per child and the log of average income for each income quintile. Since educational spending differs tremendously by the educational stage a child is in, we depict the relationship for each educational stage separately - pre-school, elementary school, middle school, and high school. Interestingly, the figures show very stable income gradients across cohorts for each education stage. As reported in Table 2, the slopes, i.e. the income elasticity of demand for private education, tend to increase as children become older. It is worth noting that all slopes are less than one, which means that, relatively speaking, the richer families do not spend as much on education. This can be seen more clearly in Table 3, which gives the fraction of family income spent on private education by quintile. The ratio of spending on private education to family income decreases with income. In other words, low-income households spend a higher fraction of their income to educate their children.

Figure 4 shows the average monthly education expenditures, including tuition, per child from birth to age 24 and their shares relative to income. We use households with one child to plot this figure because we want to focus on the variation by child's age. The vertical lines indicate the typical ages at which children enter the next level of school in Korea. Note that the education expenditures increase rapidly before children enter elementary school. Then, it continually increases at a lower speed until children graduate from high school. The peak is at age 19 when children enter university and the amount is around 500,000 KRW (similar to 500 USD) per month. The share of education expenditure in income has a similar shape. Expenditures on private education for college students would be low but tuition is much higher. This implies that 
Table 3: The ratio of expenditures on private education to income

\begin{tabular}{ccccccccc}
\hline \multirow{2}{*}{ Income } & \multicolumn{2}{c}{ Pre-School } & \multicolumn{4}{c}{ Elementary } & \multicolumn{3}{c}{ Middle } & \multicolumn{2}{c}{ High } \\
quintile & $1958-$ & $1967-$ & $1958-$ & $1967-$ & $1958-$ & $1967-$ & $1958-$ & $1967-$ \\
& 66 & 75 & 66 & 75 & 66 & 75 & 66 & 75 \\
\hline 1st & 8.9 & 8.5 & 8.3 & 9.2 & 9.5 & 8.4 & 8.3 & 6.1 \\
2nd & 6.9 & 6.4 & 6.9 & 8.0 & 8.6 & 8.1 & 6.3 & 5.4 \\
3rd & 5.5 & 6.0 & 6.6 & 7.5 & 7.7 & 7.1 & 6.1 & 5.4 \\
4th & 5.2 & 5.4 & 6.5 & 6.7 & 7.9 & 7.3 & 7.2 & 6.6 \\
5th & 3.7 & 4.5 & 4.8 & 5.2 & 5.8 & 6.4 & 6.0 & 6.3 \\
\hline
\end{tabular}

Notes: This table shows the fraction of expenditures on private education per child at each stage of education for each cohort group. The shares are calculated by dividing the average expenditures with the average income for each income quintile.

many Korean parents provide financial supports for their children's college tuition though their supports decrease rapidly from the third year in college. ${ }^{6}$

In the modeling section, we use the fraction of total life-time education spending per child in income to calibrate our model. The life-time spending per child for 25 years from birth to age 24 is 8.8 million Korean Won and $9.9 \%$ of income. To get this, we first sum the education expenditures and incomes separately across ages for 25 years and then divide the sum of expenditures with the sum of incomes.

\subsection{Intergenerational Persistence}

The human capital and income of children are affected by those of parents through different mechanisms (Solon 1999). Because parental investment could potentially be important in shaping these relationships, it is interesting to explore how this relationship look in Korea. To do so, we use our data to estimate the intergenerational persistence of income between parents and children. Specifically, we first select households with information on labor earnings (including self-employed) for both parents and children in working

\footnotetext{
${ }^{6}$ The rapid drop can be related to the conscription system in Korea. Many male students go to the army after finishing their second year in college.
} 
Figure 4: Private education expenditures by age

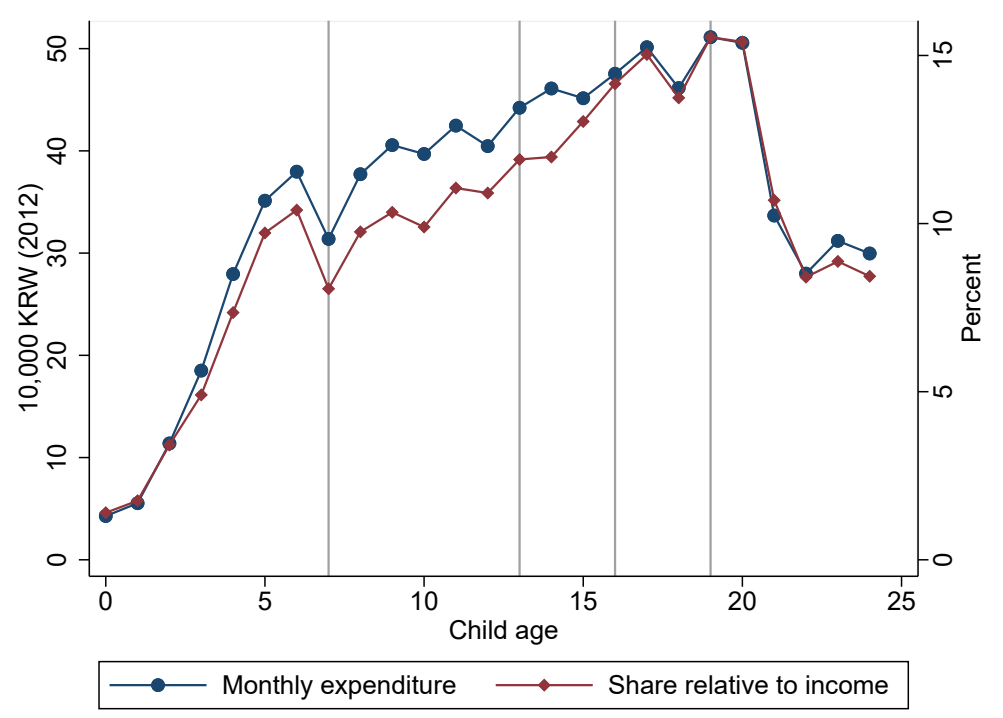

Notes: This figure shows the total education expenditures on both private and public education per child for 25 years from age 0 to 24 and their shares in household income.

ages. We focus on father's earnings because mother's working status is affected more by other factors than human capital, such as childbearing. ${ }^{7}$ Specifically, we calculate the average income of fathers aged 38 to 42 and that of children aged 29 to $33 .{ }^{8}$ Then, we regress the log income of children on the log income of father. We control for children's mean age in the regression to mitigate the lifecycle bias (Haider and Solon 2006).

The estimated intergenerational income persistence, i.e. the coefficient of log father's income is 0.31 . The estimates depend on the target ages of fathers and children. Table A. 2 in Appendix shows that the estimated elasticity ranges from 0.1 to 0.5 , partly due to the small sample. However, we note that this range is

\footnotetext{
${ }^{7}$ This is also standard in the empirical literature on intergenerational mobility (Solon 1999)

${ }^{8}$ We include households only when they have at least two observation for each person in the target ages. This process leaves 57 matches of fathers and children. The number of matches increases as the gap in the target age bands for fathers and children getting apart. However, to get a better measure of the intergenerational earnings persistence, it is better to reduce the gap in target age bands. We select the current age bands for fathers and children to balance these two factors.
} 
broadly consistent with estimates from other countries. ${ }^{9}$ Because the estimation of the intergenerational persistence is not the main goal of this paper, we take the baseline estimate of 0.31 as a target statistic in our quantitative exercise in the following sections.

\section{The Model}

In this section, we describe our model of fertility and parental investment choices with status externalities. We build on the quantity-quality literature where parents choose the number of children and how much to invest in each. ${ }^{10}$. The model is an overlapping generations model, where each generation lives for two periods: as children and as adults. As in most of the fertility literature, we assume asexual reproduction; that is, we abstract from marriage and model only a generic parent.

In contrast to much of the literature, we assume that fertility, $n$, is a discrete choice. This is not only realistic, but also naturally leads to childlessness as an equilibrium outcome for some parents. ${ }^{11}$ For some parents, the cost of having a child will be so high (relative to income) that they may prefer not to have any children.

We are interested in the relationship between income and fertility and hence need to introduce some heterogeneity that generates a cross-sectional income distribution. Parents will differ in their own human capital and hence income, which will lead them to make different fertility and education choices for their children. Yet, since human capital is endogenous in the model (each parent is a child of a previous parent), to have a non-degenerate income distribution in equilibrium, we need to introduce some exogenous heterogeneity as well. We assume people differ along two dimensions: preferences and ability. ${ }^{12}$

\footnotetext{
${ }^{9}$ For example, see Solon (1999) and Chetty et al. (2014) for evidence from the US.

${ }^{10}$ See Becker (1960), Becker and Tomes (1976) and de la Croix and Doepke (2003) among others

${ }^{11}$ The importance of distinguishing the extensive and intensive fertility choice margins has been recently emphasized by Baudin, de la Croix, and Gobbi (2015) and Aaronson, Lange, and Mazumder (2014).

${ }^{12}$ Having both dimensions gives a lot of flexibility about the shape of the fertility-income rela-
} 
Specifically, we allow parents to differ in their relative taste for own consumption vs. utility from off-springs. Ability heterogeneity enters into the human capital production function and will be described in detail below. We assume that when parents choose the number of children, they do not know their future offsprings' ability yet. However, before parents invest in their children's education, ability is realized. For simplicity, we assume that all children of the same parent will have the same ability.

A key feature of our model is a status externality. Parents care not only about the quality of their children (as in standard models), but rather about their quality relative to the quality of other parent's children. We model this by assuming the following functional form in the utility parents derive from the number, $n$, and the human capital, $h$, of their children

$$
\phi(n) \log \left(h^{\prime}-\chi \bar{h}\right)
$$

where $\bar{h}$ is the endogenous benchmark quality to which parents compare their children and $\chi \in[0,1)$ the strength of the externality. Setting $\chi=0$ turns off the externality and allows a comparison with standard models.

A parent's ex-post preferences (after all uncertainty is resolved) can then be summarized by the following utility function:

$$
b \log \left(\frac{c}{\Lambda(n)}\right)+\frac{(1-\lambda n-l)^{1-\gamma}}{1-\gamma}+\phi(n) \log \left(h^{\prime}-\chi \bar{h}\right)
$$

where $b$ is the preference shock mentioned above. We assume that it can take $N_{b}$ number of values: $b \in\left\{b_{i}\right\}_{i=1}^{N_{b}}$ with the corresponding probabilities $\left\{\pi_{i}^{b}\right\}_{i=1}^{N_{b}}$. Parents value leisure, which decreases with the number of children and labor supply $l$. We assume that a child costs $\lambda$ unit of time. The curvature of utility from leisure is captured by $\gamma$. As is standard in the literature, we introduce household equivalence scales in consumption, denoted by $\Lambda(n)$.

tionship and allows for both directions of causality. More able parents may choose more children because of an income effect, or fewer because of a substitution effect. They may also react to the quantity-quality trade-off differently and accordingly choose different numbers of children. Finally, more child-loving parents may choose to work less and hence have less income. This last channel is less common in the literature, but see for example Jones, Schoonbroodt, and Tertilt (2010). 
We assume that children's human capital is formed through three different inputs: exogenous ability $\kappa$, parental human capital $h$ and monetary education investments, $x$. Ability is drawn iid from a discrete distribution: $\kappa \in\left\{\kappa_{i}\right\}_{i=1}^{N_{\kappa}}$ with a probability mass $\left\{\pi_{i}\right\}_{i=1}^{N_{\kappa}}$. The interpretation of $h$ entering into the human capital production function is that children learn much by imitation, hence the higher the parental human capital the more can be learned. Parents choose the amount $x$ to invest into their children (per child) after $\kappa$ is realized. We assume that these components are complementary and choose the following functional form

$$
h^{\prime}=\kappa\left(\theta+x^{\alpha_{1}} h^{\alpha_{2}}\right)
$$

where $\alpha_{1}, \alpha_{2} \in(0,1)$ and $\alpha_{1}+\alpha_{2}<0$. The parameter $\theta>0$ guarantees that even if parents choose zero education for their children, they will have some baseline human capital. This can be interpreted as both raw intelligence but also publicly provided education.

As is clear from the above description, children are costly. On the one hand, there is the already explained endogenous education cost $x$. Moreover, children take time. We assume each child costs the parent's $\lambda$ units of time.

The timing within a period is as follows. Parents start the period endowed with human capital $h$ (chosen by their own parents). The preference type $b$ is then realized. Given $b$, parents choice fertility $n$, taking expectations on child ability into account. Next, the ability shock $\kappa$ is realized. Finally, parents make decisions on own consumption, labor supply, and education investments into their children.

\subsection{Decision Problem}

Given the timing assumptions, the parental decision problem can be best summarized in two steps. First, the parent makes a discrete fertility choice, not yet knowing the ability of the child. The first step choice problem thus is:

$$
\max _{n=0,1, \ldots, N_{n}}\left\{E_{\kappa} V(h, b, \kappa, n)\right\}
$$


where the household's value of having $n$ children of type $\kappa$ is given by the following choice problem

$$
\begin{aligned}
V(h, b, \kappa, n)= & \max _{c, n, x, l}\left\{b \log \left(\frac{c}{\Lambda(n)}\right)+\frac{(1-\lambda n-l)^{1-\gamma}}{1-\gamma}+\phi(n) \log \left(h^{\prime}-\chi \bar{h}\right)\right\} \\
\text { s.t. } \quad & c+x n \leq w h l \\
& h^{\prime}=\kappa\left(\theta+x^{\alpha_{1}} h^{\alpha_{2}}\right) \\
& l \in[0,1-\lambda n]
\end{aligned}
$$

To close the model, we assume that production is linear in aggregate labor. Letting $L$ be aggregate labor supply in efficiency units, output is given by $Y=A L$.

\subsection{Stationary Equilibrium}

The key object of the stationary general equilibrium is the endogenous distribution of human capital. A stationary equilibrium is a set of functions for quantities $L$, decision rules $n(h, b, \kappa), l(h, b, \kappa), c(h, b, \kappa), x(h, b, \kappa)$, and the distribution $F\left(d h, b_{i}\right)$ such that

- Given prices, households' decision problem leads to $n(h, b, \kappa), l(h, b, \kappa), c(h, b, \kappa), x(h, b, \kappa)$.

- Prices are competitively determined: $w=A$

- Markets clear:

$$
L=\sum_{i}^{N_{b}} \pi_{i}^{b} \sum_{j}^{N_{\kappa}} \pi_{j}^{\kappa} \int\left(h \times l\left(h, b_{i}, \kappa_{j}\right)\right) F\left(d h, b_{i}\right)
$$

- The stationary distribution of human capital is a fixed point:

$$
\int_{0}^{\bar{h}} F\left(d h, b_{i}\right)=\frac{\sum_{i}^{N_{b}} \pi_{i}^{b} \sum_{j}^{N_{\kappa}} \pi_{j}^{\kappa} \int_{\left\{h \mid f\left(h, b_{i}, \kappa_{j}\right) \leq \bar{h}\right\}} n\left(h, b_{i}, \kappa_{j}\right) F\left(d h, b_{i}\right)}{2(1+g)}
$$


where $f\left(h, b_{i}, \kappa_{j}\right)$ is the adult human capital implied by decision rule $x\left(h, b_{i}, \kappa_{j}\right)$ and $\kappa_{j}$ and the population growth rate is given by

$$
1+g=\frac{\sum_{i}^{N_{b}} \pi_{i}^{b} \sum_{j}^{N_{\kappa}} \pi_{j}^{\kappa} \int_{h} n\left(h, b_{i}, \kappa_{j}\right) F\left(d h, b_{i}\right)}{2} .
$$

\section{Calibration}

The model is solved numerically and calibrated to Korea. The calibration proceeds in three steps. First, some parameters are chosen externally based on direct data analogs, the literature or simple normalizations. Second, the remaining parameters are selected to match moments related to fertility and education in Korea. We use moments based on the 1967-75 Cohort described in Section 2. Third, the model predictions are compared to Korean data along several non-targeted dimensions.

\subsection{Externally chosen parameters}

We set $N_{n}=3$ because the fraction of households who have more than three children is very small (less than 2 percent). The discrete distributions for $b$ and $\kappa$ approximate log normal distributions,

$$
\begin{aligned}
\log \kappa & \sim \mathcal{N}\left(\mu_{\kappa}, \sigma_{\kappa}^{2}\right) \\
\log b & \sim \mathcal{N}\left(\mu_{b}, \sigma_{b}^{2}\right)
\end{aligned}
$$

with $N_{\kappa}=N_{b}=12$.

The parameter $\gamma$ governs the curvature of the utility function with respect to leisure. We choose $\gamma=2$ so that the implied intertemporal elasticity of substitution is 0.5 . The next parameter $\lambda$ captures time costs of children. In our samples from the KLIPS, the average parental time spent with children aged up to 18 is 5.7 hours per week. ${ }^{13}$ Assuming that a time endowment that can be

\footnotetext{
${ }^{13}$ In the data, mothers spend more time with children on average. Because our model does not address gender differences, we use the average including both mothers and fathers.
} 
Table 4: Parameters calibrated internally

\begin{tabular}{|c|c|c|c|}
\hline Parameter & Target statistics & Model & Data \\
\hline 0.893 & $\operatorname{Pr}(\#$ child $=1)$ & 0.168 & 0.188 \\
\hline 1.491 & $\operatorname{Pr}(\#$ child $=2)$ & 0.646 & 0.608 \\
\hline 1.789 & $\operatorname{Pr}(\#$ child $\geq 3)$ & 0.123 & 0.135 \\
\hline$\sigma_{\kappa}=$ & Gini income & 0.258 & 0.297 \\
\hline 0.677 & Avg total hours worked & 0.314 & 0.303 \\
\hline 0.481 & Income elasticity of fertility & 0.148 & 0.113 \\
\hline 0.057 & Income (semi) elasticity of childless & -0.037 & -0.092 \\
\hline 1.163 & Avg investment-income ratio & 0.090 & 0.099 \\
\hline 0.190 & Income elasticity of educ spending & 0.779 & 0.77 \\
\hline 0.618 & Intergenerational elasticity & 0.284 & 0.31 \\
\hline
\end{tabular}

allocated is 100 hours per week, this leads to the value of 0.041 . The next two parameters, $\mu_{\kappa}$ and $A$ are set to 1 as normlization. For the equivalence scale $\Lambda(n)$, we use the OECD modified equivalence scale.

In principle, the benchmark human capital $\bar{h}$ in our model can be any moment of the equilibrium human capital distribution. Our baseline model assumes that it is the 9th decile of the human capital distribution. Note that in our framework, the choice of this moment is not of the first-order importance because the feedback from the distribution to individual's decisions depends on not only $\bar{h}$ but also $\chi$, the latter of which is calibrated internally (see discussion below).

\subsection{Calibrated Parameters}

The remaining parameters are calibrated to match moments in the data. The data targets are obtained from Section 2 . The calibrated parameters and target statistics are summarized in Table 4.

Although the relationship between parameters and target statistics is not a clear one-to-one mapping because a parameter affects multiple moments in the model, it is instructive to explain how they are linked. The first three parameters in Table 4 govern the utility of having $n$ child: $\phi(n)$. Because fertility is a discrete choice between 0 and 3 , it is unnecessary to impose a parametric functional form 
on $\phi(n)$, as in the literature that assumes a continuous fertility choice. Therefore, we let it be non-parametric, and assume that $\phi(n)=\phi_{n}$ and $\phi(0)=0$. This leads to three parameters $\left\{\phi_{n}\right\}_{n=1}^{3}$, which are calibrated to match the distribution of fertility choices in the data.

The parameter $\sigma_{\kappa}$ determines the variability of child ability. Because the ability shock is an important exogenous source of income heterogeneity in the model, we choose the Gini index of income as a target statistic. The next two parameters $\mu_{b}$ and $\sigma_{b}$ shape the heterogeneity in preference. Because a higher $\mu_{b}$ leads to greater labor supply, a natural target is set to be the average total hours worked. An important reason for having the preference heterogeneity is to have a mechanism in the model that tends to generate a negative fertility-income relationship (Jones and Tertilt 2008). In other words, the greater variability of $b$ makes the equilibrium fertility-income relationship less positive (or more negative). Therefore, we choose the income elasticity of fertility obtained in Section 2 as a target statistic.

The parameter $\chi$ governs the strength of status externalities given $\bar{h}$. In our model, childlessness is closely linked to the concern for the quality of children. In aggregate, it is clear to see that status externality leads to higher private educational spending and lower fertility. In the presence of heterogeneity, this effect may differ across income groups. To see this, note that for the utility of having an additional child to be positive,

$$
\begin{aligned}
\kappa\left(\theta+x^{\alpha_{1}} h^{\alpha_{2}}\right)-\chi \bar{h} & >1 \\
x & >\left(\frac{1+\chi \bar{h}}{\kappa}-\theta\right)^{\frac{1}{\alpha_{1}}} h^{-\frac{\alpha_{2}}{\alpha_{1}}}
\end{aligned}
$$

which gives the minimum required investment

$$
x_{\min }=\left(\frac{1+\chi \bar{h}}{\kappa}-\theta\right)^{\frac{1}{\alpha_{1}}} h^{-\frac{\alpha_{2}}{\alpha_{1}}} .
$$

As this is decreasing in $h$ and this gradient becomes steeper with a greater $\chi$, the degree of externality can shape the income gradient of childlessness. Thus, we include the income (semi) elasticity of childless (-0.092) as a target statistic. 
Table 5: Fertility across income quintile

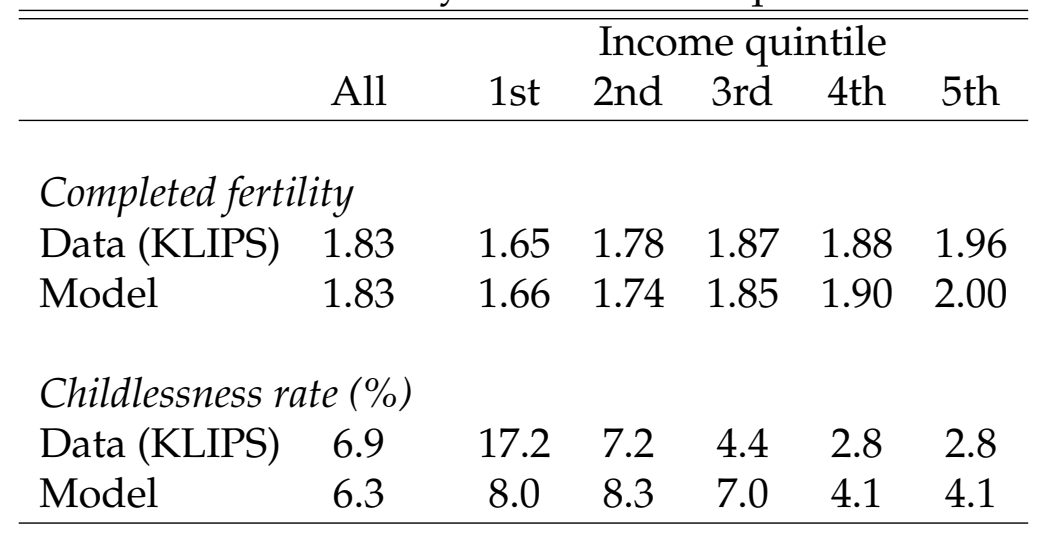

The next parameter in Table $4, \theta$, affects the marginal utility of additional education spending. In other words, a higher $\theta$ reduces an incentive to invest $x$, holding others constant. Thus, the next target statistic for this parameter is the average investment relative to income, which is $9.9 \%$. The last two parameters also govern the human capital production technology. For $\alpha_{1}$, we choose the income elasticity of educational spending, as documented in Section 2. As the elasticity varies depending on the age of child, we choose the mean value of 0.77 as a target statistic. Note that $\alpha_{2}$ governs the strength of human capital transmission from parents to children. Therefore, our last target statistic is the intergenerational elasticity of 0.31 , as discussed above.

Table 4 shows the calibrated parameters and the target statistics implied by the model as well as computed from the data. Overall, our simple model is able to match the target moments quite well.

\subsection{Non-targeted Moments}

Our calibration strategy targets the overall income gradient of fertility along the total margin as well as along the extensive margin. It is interesting to see how the model performs across income quintile. Table 5 shows that the model does a good job of matching the fertility rate across income quintile, especially in terms of completed fertility. 
Figure 5: Status externality and fertility across income quintile

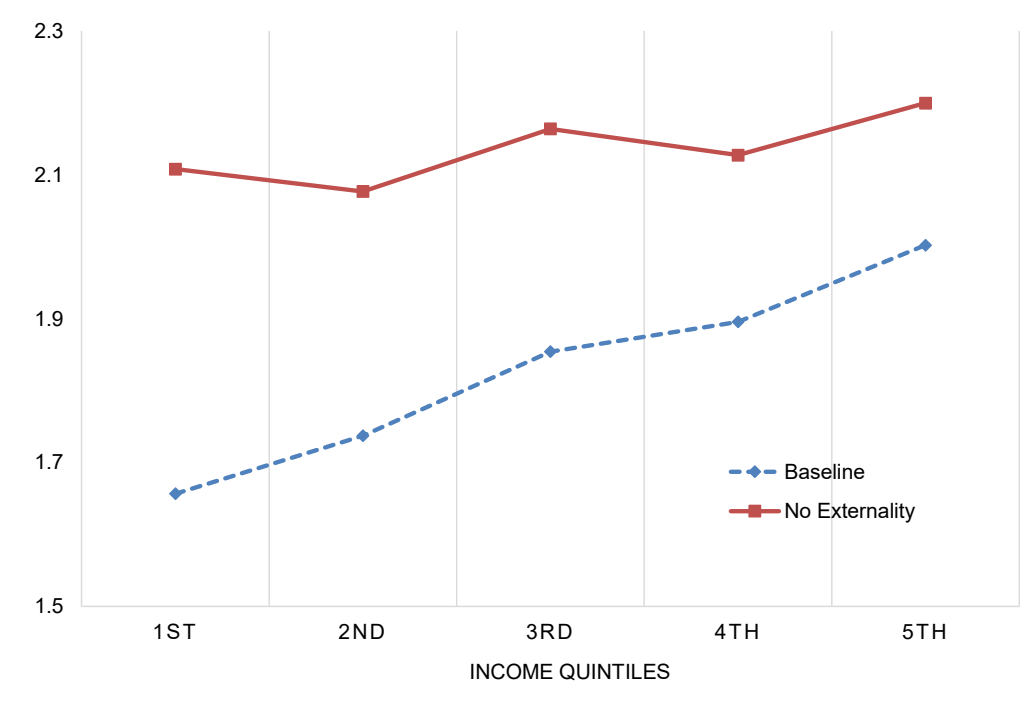

\section{The Role of the Status Externality}

We now use the baseline model to explore how the presence of status externalities affect households' decision on fertility and educational investment. In particular, we put emphasis on its heterogeneous effects across income quintile.

To understand the role of status externalities, we shut down the externality by setting $\kappa=0$. Figure 5 shows how fertility rates across income quintile change in the absence of the externality. Two points are worth noting. First, note that the overall fertility rate is higher across all income quintiles. The aggregate fertility rate is considerably higher at 2.14 relative to 1.83 in the baseline model with the status externality. Second, it is important to note that the increase in fertility rates is relatively higher among low income groups. More precisely, the income elasticity of fertility is much lower at 0.034 without the externality, compared to 0.148 in the baseline model with the externality.

Table 6 also reports childlessness rates and educational investment per child 
Table 6: Effects of status externality across income quintile

\begin{tabular}{lccccc}
\hline \hline & \multicolumn{5}{c}{ Income quintile } \\
& 1st & 2nd & 3rd & 4th & 5th \\
\hline Childlessness rate (\%) & & & & & \\
Model: Baseline & 8.0 & 8.3 & 7.0 & 4.1 & 4.1 \\
Model: No Externality & 1.5 & 1.5 & 2.5 & 1.8 & 2.2 \\
& & & & & \\
Investment per child & & & & & \\
Model: Baseline & 0.039 & 0.054 & 0.065 & 0.078 & 0.108 \\
Model: No Externality & 0.027 & 0.038 & 0.049 & 0.059 & 0.088 \\
Change relative to baseline & $-16.4 \%$ & $-14.9 \%$ & $-12.1 \%$ & $-12.1 \%$ & $-8.7 \%$ \\
\hline
\end{tabular}

across income quintile. The top panel shows that in the absence of the externality, the childlessness rate becomes much flatter. This is in sharp contrast to the baseline model that features relatively higher childlessness rates (around 8 percent) among the low income households.

The bottom panel shows how parental investment in children changes depending on the presence of the externality across income quintile First, it is clear to see that households generally spend less in private education when their motive to catch up with others disappears. More importantly, we note that this effect is relatively stronger among the low income households, meaning that low income households in our baseline model are investing more aggressively (measured by the ratio of spending to income) in order to catch up. This puts more pressure among the low income households when it comes to the choice of having a child, thereby illustrating why the status externality is able to influence the income gradient of fertility.

\subsection{Inefficiency}

Externalities generally lead to inefficiencies. Before exploring the exact nature of the inefficiency in our model, one first needs to note that Pareto efficiency is not defined in this model as different allocations will naturally differ in population size due to the endogenous fertility rate. We thus use the concept $\mathcal{A}$-Efficiency introduced by Golosov, Jones, and Tertilt (2007). This is fairly close to the usual 
notion of Pareto efficiency but is well-defined for our setting.

The equilibrium described above is clearly not $\mathcal{A}$-Efficiency. When parents care about the education of their children relative to other parent's children, parents will over-invest into their children. This makes children costly and will therefore simultaneously lead to an under-investment in the number of children. In other words, there exist other allocations where education is lower, fertility is higher, and none of the (born) people is worse off. The first best can be obtained by solving the following planning problem.

TBW

\section{Policy}

The inefficiency described in the previous section offers room for policy interventions. We now consider several government policy experiments using the benchmark model economy. ${ }^{14}$

Specifically, we extend the budget constraint of the household to incorporate government policy variables:

$$
c+\left(1+\tau_{x}\right) x n \leq w h l+T+T_{n}(n)
$$

where $\tau_{x}$ denotes tax (or subsidy) on private education investment and $T_{n}(n)$ are pro-natal transfers. We assume that government budget is balanced by adjusing lump-sum tax (or transfer) $T$ whenever government policy leads to extra spending (or revenue).

\subsection{Taxing or subsidizing private education expenses}

In this subsection, we first consider the educational tax experiment. This is a natural starting point because equilibrium in our model features inefficiently

\footnotetext{
${ }^{14}$ As a caveat, it should be mentioned that for now we compare the stationary equilibria that result from the policies, not taking transitional dynamics into account.
} 
Table 7: Policy experiment: private education tax

\begin{tabular}{lcccc}
\hline \hline Model & Bench & \multicolumn{3}{c}{$\tau_{x}=$} \\
\cline { 3 - 5 } & -mark & 0.10 & 0.20 & 0.30 \\
\hline & & & & \\
Fertility rate $n$ & 1.83 & 1.81 & 1.79 & 1.78 \\
Avg $x$ per kid/income & $9.0 \%$ & $8.2 \%$ & $7.6 \%$ & $7.0 \%$ \\
& & & & \\
Income elasticity of $n$ & .148 & .153 & .143 & .138 \\
Income elasticity of $x$ & .779 & .763 & .751 & .744 \\
& & & & \\
Avg labor supply & .314 & .311 & .309 & .307 \\
Avg human capital & .764 & .747 & .734 & .720 \\
Avg utility (equal weight) & & -0.012 & -0.023 & -0.037 \\
\hline
\end{tabular}

low fertility due to over-investment. We consider the tax rate of $10 \%$ to $30 \%$.

Table 7 summarizes the result.

It is worth noting several observations. First, the educational tax is successful in reducing parental investment quite substantially. However, note that lower quality does not necessarily lead to greater quantity of children: the fertility rate actually falls when the tax rate increases. A higher education tax raises the price of children by making harder to attain a certain quality of children, thereby reducing demands for both quantity and quality of children.

Given the above result that the education tax reduces fertility, we also consider a educational subsidy exercise to explore the possibility of raising fertility rates. Note that the subsidy is simply a negative $\tau_{x}$ in our specification. We consider the subsidy rate of $10 \%$ to $30 \%$. Table 8 summarizes the result.

As expected, the educational subsidy is able to increase the fertility rate. At the same time, we can see that educational spending per child also increases quite substantially. By distorting the relative price of children (through subsidizing quality), parents now demand for children along both quantity and quality margins. 
Table 8: Policy experiment: private edcuation subsidy

\begin{tabular}{lcccc}
\hline \hline & Bench & \multicolumn{3}{c}{$\tau_{x}=$} \\
\cline { 3 - 5 } & -mark & -.10 & -.20 & -.30 \\
\hline & & & & \\
Fertility rate $n$ & 1.83 & 1.85 & 1.88 & 1.90 \\
Avg $x$ per kid/income & $9.0 \%$ & $9.8 \%$ & $10.8 \%$ & $12.1 \%$ \\
& & & & \\
Income elasticity of $n$ & .148 & .163 & .179 & .208 \\
Income elasticity of $x$ & .779 & .795 & .818 & .851 \\
Avg labor supply & & & & \\
Avg human capital & .314 & .318 & .323 & .329 \\
Avg utility (equal weights) & .764 & .784 & .809 & .839 \\
\hline
\end{tabular}

Table 9: Policy experiment: pro-natal transfers

\begin{tabular}{lcccc}
\hline \hline & Bench & \multicolumn{3}{c}{$\psi=$} \\
\cline { 3 - 5 } & -mark & 0.01 & 0.02 & 0.03 \\
\hline & & & & \\
Fertility rate $n$ & 1.83 & 1.91 & 1.99 & 2.07 \\
Avg $x$ per kid/income & $9.0 \%$ & $8.8 \%$ & $8.6 \%$ & $8.4 \%$ \\
& & & & \\
Income elasticity of $n$ & .148 & .102 & .056 & -.002 \\
Income elasticity of $x$ & .779 & .802 & .829 & .855 \\
& & & & \\
Avg labor supply & .314 & .314 & .312 & .311 \\
Avg human capital & .764 & .754 & .744 & .733 \\
Avg utility (equal weights) & & -0.015 & -0.031 & -0.050 \\
\hline
\end{tabular}

\subsection{Pro-natal transfers}

We now consider the effects of pro-natal transfers. Specifically, we assume a simple transfer function that is linear in the number of children: $T_{n}(n)=\psi n$. We consider three different values of $\psi: \psi \in\{0.01,0.02,0.03\}$. Note that this type of income-independent transfers given to households with children has been implemented in Korea in recent years. As this type of transfers is present in Germany (Kindergeld), the largest value of 0.3 is chosen to be comparable to the child allowance in Germany (allowance of 200 euros per month for each child when GDP per capita is approximately 40,000 euros) for ease of comparison. 
Table 9 summarizes the result. First, it clearly shows that it is possible to increase the fertility rate by incentivizing parents to have more children through cash transfers. However, the effects are relatively weak considering that the required budget for $\psi=0.3$ is $8.5 \%$ of GDP, whereas the fertility rate increases only from 1.83 to $2.07 . .^{15}$

\section{Conclusion}

TBW

\footnotetext{
${ }^{15}$ This is in line with some empirical evidence on the positive yet weak effects on pro-natal transfers on fertility (Hong et al. 2016).
} 


\section{References}

Aaronson, Dan, Fabian Lange, and Bhash Mazumder. 2014. "Fertility Transitions Along the Extensive and Intensive Margin." American Economic Review 104 (11): 3701-24.

Abel, Andrew B. 1990. "Asset Prices Under Habit Formation and Catching Up with the Joneses." The American Economic Review 80, no. 2.

Bar, Michael, Moshe Hazan, Oksana Leukhina, David Weiss, and Hosny Zoabi. 2018. "Why did Rich Families Increase their Fertility? Inequality and Marketization of Child Care." Journal of Economic Growth 23 (4): 427-463.

Baudin, Thomas, David de la Croix, and Paula E. Gobbi. 2015. "Fertility and Childlessness in the United States." American Economic Review 105 (6): 1852-82.

Becker, Gary S. 1960. "An Economic Analysis of Fertility." Demographic and Economic Change in Developed Countries, Universities - National Bureau Conference Series no. 11. Princeton University Press.

Becker, Gary S, and Nigel Tomes. 1976. "Child Endowments and the Quantity and Quality of Children." Journal of Political Economy 84 (4): S143-62 (August).

Chetty, Raj, Nathaniel Hendren, Patrick Kline, and Emmanuel Saez. 2014. "Where is the land of opportunity? The geography of intergenerational mobility in the United States." The Quarterly Journal of Economics 129 (4): 1553-1623.

de la Croix, David, and Matthias Doepke. 2003. "Inequality and Growth: Why Differential Fertility Matters." American Economic Review 93 (4): 1091-1113.

Easterlin, Richard A. 1966. "On the Relation of Economic Factors to Recent and Projected Fertility Changes." Demography 3 (1): 131-153.

Gali, Jordi. 1994. "Keeping Up with the Joneses: Consumption Externalities, Portfolio Choice, and Asset Prices." Journal of Money, Credit and Banking 26 (1): $1-8$.

Genicot, Garance, and Debraj Ray. 2017. "Aspirations and Inequality." Econometrica 85 (2): 489-519. 
Golosov, Mikhail, Larry E. Jones, and Michèle Tertilt. 2007. "Efficiency with Endogenous Population Growth." Econometrica 75 (4): 1039-1071.

Guner, Nezih, Remzi Kaygusuz, and Gustavo Ventura. 2019. “Child-Related Transfers, Household Labor Supply and Welfare." CEMFI, Unpublished Manuscript.

Haider, Steven, and Gary Solon. 2006. "Life-Cycle Variation in the Association between Current and Lifetime Earnings." American Economic Review 96 (4): 1308-1320.

Hong, Sok Chul, Young Il Kim, Jae Young Lim, and Mee Young Yeo. 2016. "Pro-Natalist Cash Grants and Fertility: A Panel Analysis." Korean Economic Review 32 (2): 331-354.

Jones, Larry E., Alice Schoonbroodt, and Michèle Tertilt. 2010. “Fertility Theories: Can they explain the Negative Fertility-Income Relationship?" In Demography and the Economy, edited by John B. Shoven, 43-100. University of Chicago Press.

Jones, Larry E., and Michèle Tertilt. 2008. "An Economic History of the Relationship Between Occupation and Fertility - U.S. 1826-1960." In Frontiers of Family Economics, Volume 1. ed. Peter Rupert, Bingley, UK: Emerald Group Publishing Limited.

Ljungqvist, Lars, and Harald Uhlig. 2000. "Tax Policy and Aggregate Demand Management Under Catching Up with the Joneses." American Economic Review 90 (3): 356-366.

Nishimura, Kazuo, and Junsen Zhang. 1992. "Pay-as-You-Go Public Pensions with Endogenous Fertility." Journal of Public Economics 48 (2): 239-258.

Schoonbroodt, Alice, and Michele Tertilt. 2014. "Property Rights and Efficiency in OLG Models with Endogenous Fertility." Journal of Economic Theory 150:551-582.

Solon, Gary. 1999. "Intergenerational mobility in the labor market." In Handbook of labor economics, Volume 3, 1761-1800. Elsevier. 


\section{A Appendix Tables}

Table A.1: Fertility and income (couples only)

\begin{tabular}{ccccc}
\hline \multirow{2}{*}{ Income quintile } & \multicolumn{2}{c}{ Number of children } & \multicolumn{2}{c}{ Childlessness rate (\%) } \\
& $1967-75$ & $1958-66$ & $1967-75$ & $1958-66$ \\
\hline 1th & 1.92 & 1.90 & 3.60 & 5.15 \\
2nd & 2.00 & 1.87 & 0.90 & 3.00 \\
3rd & 1.99 & 1.90 & 1.36 & 3.43 \\
4th & 2.03 & 1.88 & 0.90 & 2.15 \\
5th & 2.05 & 1.97 & 0.90 & 3.00 \\
\hline
\end{tabular}

Notes: This table shows the average fertility rate, the childlessness rate in each income quintile for each cohort group excluding single households.

Table A.2: Intergenerational elasticity of earnings

\begin{tabular}{cccccc}
\hline & \multicolumn{3}{c}{ Father's age } \\
& $36-40$ & $37-41$ & $38-42$ & $39-43$ & $40-44$ \\
\hline $\begin{array}{c}\text { Child's age } \\
\text { 27-31 }\end{array}$ & 0.16 & 0.14 & 0.18 & 0.22 & 0.18 \\
$28-32$ & 0.10 & 0.15 & 0.22 & 0.21 & 0.21 \\
$29-33$ & 0.21 & 0.24 & 0.31 & 0.31 & 0.24 \\
$30-34$ & 0.33 & 0.37 & 0.46 & 0.47 & 0.30 \\
$31-35$ & 0.22 & 0.37 & 0.45 & 0.53 & 0.32 \\
\hline
\end{tabular}

Notes: This table shows the estimated intergenerational earnings persistence when ages of fathers and children vary. 


\section{B Appendix Figures}

Figure B.1: Fertility by income quintiles (couples only)

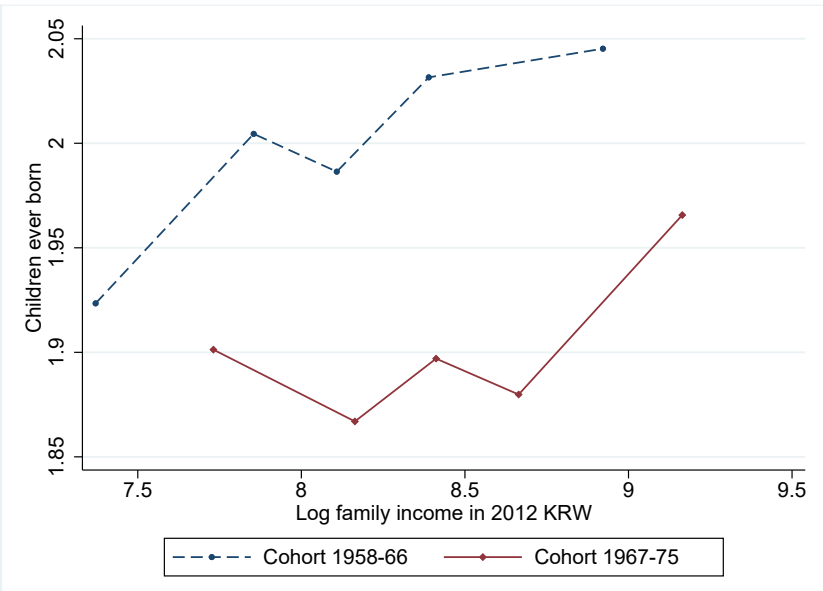

Figure B.2: Childlessness rate by income quintiles (couples only)

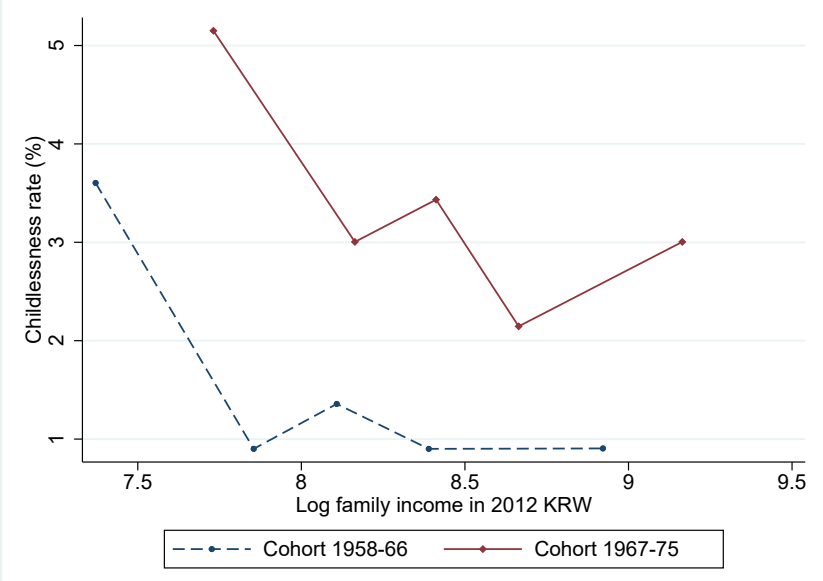

